\title{
Laparoscopic Liver Resection for Hepatocellular Carcinoma in Cirrhosis: Long-Term Outcomes
}

\author{
Giulio Belli Corrado Fantini Andrea Belli Paolo Limongelli \\ Department of General and Hepato-Pancreato-Biliary Surgery, S.M. Loreto Nuovo Hospital, Naples, Italy
}

\section{Key Words}

Hepatic resection - Hepatocellular carcinoma

Laparoscopic liver resection • Liver surgery

\begin{abstract}
Background: Few data regarding survival or pattern of recurrence after laparoscopic liver resection (LLR) for hepatocellular carcinoma (HCC) on cirrhosis have been reported so far. Methods: A retrospective analysis of a prospectively maintained database of 109 laparoscopic interventional procedures performed for HCC in cirrhotic liver between 2000 and 2008 was conducted. Results: Sixty-five patients underwent an LLR. Morbidity rates were $20 \%$ (13/65), whereas there was only 1 death (1.5\%). Reoperation was required in 2 patients. The overall mean postoperative hospital stay was $8.2(2.6 ; 3-15)$ days. The actuarial overall $1-, 3$-, and 5-year survival rates were 95,70 , and $55 \%$, respectively, with a median overall survival of 75 months. Excluding the one hospital death, the actuarial 1-, 3-, and 5-year disease-free survival rates were 81,62 , and $32 \%$, respectively, with a median overall disease-free survival of 42 months (95\% confidence interval, Cl: 18-65). On multivariate analysis, tumor grade (OR: 3.5, $95 \% \mathrm{Cl}: 1.1-10.7, \mathrm{p}=0.026)$ and microvascular invasion (OR: $4.9,95 \% \mathrm{Cl}: 1.2-18.8, \mathrm{p}=0.020$ ) resulted as independent pre-
\end{abstract}

dictors of overall survival. On multivariate analysis, gender (OR: 3.4, 95\% Cl: 1.1-10.2, $\mathrm{p}=0.023$ ), satellite tumor (OR: 4.3, 95\% Cl: $1.5-12.3, p=0.006)$, microvascular invasion (OR: 3.3 , $95 \% \mathrm{Cl}: 1.0-10.1, \mathrm{p}=0.036$ ) and surgical margin (OR: $3.7,95 \%$ $\mathrm{Cl}: 1.0-10.1, p=0.036$ ) were identified as independent prognostic predictors of better disease-free survival. After a median follow-up of 29 (range 3-81) months, 31 (48\%) out of 64 patients had recurrence. The cumulative recurrence rates at 1,3 , and 5 years were 19,39 , and $68 \%$, respectively. Conclusion: This prospective observational study has confirmed the feasibility and safety of LLR in selected patients with HCC in cirrhotic liver, and proved that it can warrant long-term outcome similar to those reported with the traditional open approach.

Copyright $\odot 2011$ S. Karger AG, Basel

\section{Introduction}

Hepatocellular carcinoma (HCC) is the most common liver primary cancer in western countries with an increased incidence in patients with chronic liver disease, mostly owing to hepatitis $\mathrm{B}$ or C infections [1]. It is mostly diagnosed when small and asymptomatic by screening that has been shown to improve survival outcome [2].

\section{KARGER}

Fax +41613061234

E-Mail karger@karger.ch

www.karger.com
(C) 2011 S. Karger AG, Basel

$0253-4886 / 11 / 0282-0134 \$ 38.00 / 0$

Accessible online at:

www.karger.com/dsu
Prof. G. Belli

Via Cimarosa 2/A

IT-80127 Naples (Italy)

Tel. +390812542731

E-Mail chirurgia.loretonuovo@tin.it 
Liver transplantation is a potentially curative treatment for HCC in patients with underlying chronic liver disease, but cannot be applied on a large scale due to patient's age and alcohol abuse, associated diseases and donor shortage [3]. Therefore, other therapeutic options such as hepatic resection and percutaneous techniques (e.g. ethanol injection and radiofrequency ablation) are needed either as bridging treatments or alternative management for those unsuitable for liver transplant.

Open liver resection still detains a paramount role in the curative strategy of HCC in patients with an adequate liver function [4]. With the improvements of new technology and equipment, laparoscopic liver resection (LLR) has been progressively developed, and is now considered a safe procedure even in the management of liver tumors, if performed by experienced surgeons [5].

In line with previous published data $[5,6]$, the present authors have already shown good operative and oncological mid-term results of LLS in patients with HCC on cirrhosis [7]. However, few studies have reported survival outcome or pattern of recurrence after LLR for HCC on cirrhosis.

The aim of this study was to evaluate morbidity and mortality rates, survival and pattern of recurrence after LLR for HCC in patients with cirrhosis.

\section{Methods}

\section{Patient Selection}

A prospective electronic database of all patients treated by laparoscopic interventional procedures for either benign or malignant liver disease between May 2000 and December 2008 at the Department of General and Hepato-Pancreato-Biliary Surgery, S.M. Loreto Nuovo Hospital, Naples, Italy, was reviewed.

Patients were preoperatively assessed according to a specified protocol including blood examinations, abdominal ultrasound, angio-computed tomography (CT) scan, esophagogastroduodenoscopy and spirometry. In selected patients, an angio-magnetic resonance or, more recently, a contrast-enhanced harmonic sonography was performed. Hepatic function was evaluated according to the Child-Pugh classification of liver dysfunction.

Patients with well-compensated chronic liver disease (ChildPugh class A/B low grade) without signs of severe portal hypertension (esophageal varices less than F2 [8]) and with a platelet count of at least $80 \times 10^{9} / 1$ were eligible for liver resection. Those with complicated cirrhosis (Child-Pugh class C or B high grade) or whose American Society of Anesthesiologists (ASA) grade exceeded III were excluded from resection. The main selection criteria included exophytic or subcapsular tumors localized to the left (segments II, III, IVb) or peripheral right (segments V, VI) segments with a maximum lesion size of $5 \mathrm{~cm}$. Patients with lesions larger than $5 \mathrm{~cm}$ (unless pedunculated or located in the left lateral segments) or requiring complicated procedures such as major vascular resection were selected for an open approach. In the last 2 years of the study, a pilot prospective evaluation of major LLR was started, in which the indication for a laparoscopic approach was extended to tumors greater than $5 \mathrm{~cm}$.

\section{Surgical Technique}

Liver resections were defined according to the Brisbane 2000 classification [9]. Atypical resections were generally reserved for small peripheral lesions, whereas anatomical resections were performed when it was deemed that hepatic functional reserve was sufficient. Liver resection was defined as minor (two or fewer segments) or major (at least three segments) according to Couinaud's classification.

The detailed laparoscopic surgical technique has been described previously $[10,11]$. Briefly, the patient was placed supine, in the 'French' position with the primary surgeon positioned between the legs. Patients with lesions sited in the right lateral sector were placed in a left lateral decubitus position [12]. With an open technique, continuous carbon dioxide pneumoperitoneum was induced at a pressure of $<12 \mathrm{~mm} \mathrm{Hg}$ to avoid gas embolism. A standard diagnostic and staging laparoscopy was followed by intraoperative ultrasonography to improve laparoscopic staging and assist liver resection. In some patients, a tape was placed around the porta hepatis by the use of Endo Retract ${ }^{\mathrm{TM}}$ Maxi (Tyco Healthcare, Norwalk, Conn., USA) and passed through a 16-Fr rubber drain, to be used as a tourniquet to enable a Pringle maneuver to be performed if necessary. Parenchymal transection was performed using a harmonic scalpel (UltraCision; Ethicon Endosurgery, Cincinnati, Ohio, USA) or a LigaSure ${ }^{\mathrm{TM}}$ Five device (Valleylab, Boulder, Colo., USA). In the case of left lateral sectionectomy or major hepatic resection, transection of the liver parenchyma was performed together with sectioning of the portal and hepatic vein pedicles, by use of consecutive linear staplers (vascular cartridge). The resected undivided specimen was placed in a plastic bag and externalized through the slightly enlarged periumbilical incision or a horizontal minilaparotomy in the suprapubic region, or from the GelPort laparoscopic system (Applied Medical, RanchoSanta Margarita, Calif., USA) positioned for a hand-assisted technique through a $7-\mathrm{cm}$ incision in the right subcostal area.

\section{Postoperative Evaluation}

Morbidity was graded according to Clavien's classification [13]. Patient follow-up was based on regular outpatient clinic visits every 3 months, and information obtained from medical records, correspondence and telephone contact. The following parameters were evaluated: duration of operation, need for and duration of Pringle maneuver, blood loss, transfusion rate, pathological margins, postoperative complications, 30-day mortality, hospital stay, and 1- and 3-year overall and disease-free survival. Clinicopathological factors, including age, sex, ASA grade, preoperative $\alpha$-fetoprotein (AFP) level, hepatitis serology, esophageal varices, number of tumors (single vs. multiple), tumor size, surgical margin, microscopic vascular invasion (defined as the presence of tumor emboli within the central veins or portal or capsular vessels) and grade of the primary tumor as defined by Edmondson and Steiner [14], were investigated. Recurrence was diagnosed based on typical imaging findings at contrast-enhanced CT and an increased serum AFP level. If necessary, hepatic angiography, CT after administration of lipiodol or con- 
Table 1. Preoperative and perioperative data and tumor characteristics $(n=65)$

\begin{tabular}{|c|c|}
\hline \multicolumn{2}{|l|}{ Preoperative data } \\
\hline Age, years & $63.2 \pm 6.8(48-80)$ \\
\hline Males:females & $38 / 27$ \\
\hline \multicolumn{2}{|l|}{ Child-Pugh grade } \\
\hline A & $58(89)$ \\
\hline $\mathrm{B}$ & $7(11)$ \\
\hline Esophageal varices (F1) & $20(30)$ \\
\hline ASA status $(1 / 2 / 3)$ & $19 / 33 / 13$ \\
\hline \multicolumn{2}{|l|}{ Perioperative data } \\
\hline \multicolumn{2}{|l|}{ Tumor location } \\
\hline Segments V-VI-VII-VIII & $29(44)$ \\
\hline Segments II-III-IV & $28(43)$ \\
\hline Bilobar & $9(13)$ \\
\hline \multicolumn{2}{|l|}{ Resection } \\
\hline Major ( $\geq 3$ segments) & $6(10)$ \\
\hline Minor ( $\leq 2$ segments $)$ & $59(90)$ \\
\hline Operating time, $\min$ & $169 \pm 46.0(80-300)$ \\
\hline Blood loss, ml & $311 \pm 180(100-1,200)$ \\
\hline Transfusion & $7(10.7)$ \\
\hline Clamping & $2(3.0)$ \\
\hline Morbidity & $13(20)$ \\
\hline Deaths & $1(1.5)$ \\
\hline Hospital stay, days & $8.2(2.6 ; 3-15)$ \\
\hline \multicolumn{2}{|l|}{ Tumor characteristics } \\
\hline \multicolumn{2}{|l|}{ AFP } \\
\hline$\leq 400 \mathrm{ng} / \mathrm{ml}$ & 56 \\
\hline$>400 \mathrm{ng} / \mathrm{ml}$ & 9 \\
\hline Tumor size, $\mathrm{cm}$ & $3.8(1.4 ; 1-9)$ \\
\hline \multicolumn{2}{|l|}{ Tumor number } \\
\hline Solitary & $53(81)$ \\
\hline Multiple & $12(19)$ \\
\hline \multicolumn{2}{|l|}{ Resection margins } \\
\hline$<1 \mathrm{~cm}$ & $9(14)$ \\
\hline$>1 \mathrm{~cm}$ & $56(86)$ \\
\hline Invaded margins & 0 \\
\hline \multicolumn{2}{|l|}{ Satellite tumor } \\
\hline No & $53(81)$ \\
\hline Yes & $12(19)$ \\
\hline \multicolumn{2}{|l|}{ Edmonson-Steiner grade } \\
\hline I & $17(26)$ \\
\hline II & $26(40)$ \\
\hline III & $22(34)$ \\
\hline \multicolumn{2}{|l|}{ Microvascular invasion } \\
\hline Yes & $23(35)$ \\
\hline No & $42(65)$ \\
\hline
\end{tabular}

Figures in parentheses indicate range, percentage, or mean. trast-enhanced ultrasonography and fine-needle aspiration cytology were used for confirmation. All recurrences were recorded prospectively in the database immediately after confirmation of the diagnosis, and the site, number and size of recurrent tumors were documented. Patterns of recurrence were classified as follows: solitary, oligonodular (two or three tumor nodules) and multinodular (four or more lesions) intrahepatic recurrence (IHR), extrahepatic recurrence (EHR) and concurrent IHR and EHR.

\section{Statistical Analysis}

Continuous clinicopathological data were expressed as either median (range) or mean (SD; range) as appropriate. Categorical variables were analyzed by means of the $\chi^{2}$ test or Fisher's exact test. Overall survival was calculated from the date of operation to date of death or last follow-up. Disease-free survival was calculated from the date of operation to the date of recurrence or last follow-up. Overall survival and disease-free survival probabilities were estimated by the Kaplan-Meier method and compared by means of the log rank test. The Cox proportional hazards model was used for multivariate analysis. $\mathrm{p}<0.050$ was considered statistically significant.

\section{Results}

A total of 109 patients with a diagnosis of HCC underwent laparoscopic interventional procedures. Sixty-five patients with a mean age of $63.2 \pm 6.8$ underwent LLR. Sixty-one out of 65 patients (94\%) were seropositive for hepatitis HCV-Ab, 2 (3\%) were seropositive for hepatitis $B$ virus surface antigen (HBs-Ag), 1 (1.5\%) patient was seropositive for both HBs-Ag and HCV-Ab, and 1 (1.5\%) patient had a nonviral cirrhosis.

Patient data are summarized in table 1 . Among 65 laparoscopic procedures, there were 23 subsegmentectomies, 17 left lateral sectionectomies, 19 segmentectomies and 6 major laparoscopic resections (5 right and 1 left hepatectomy). There were 5 hand-assisted procedures: 3 right hepatectomies, 1 left hepatectomy and 1 subsegmentectomy on segment IV.

The average tumor size was $3.8 \pm 1.3$ (range $1-9) \mathrm{cm}$. Conversion was needed in 7 out of 65 patients (10.7\%). The median operative time was 170 (range 80-300) min. The median blood loss was 300 (range 100-1,200) ml with perioperative blood transfusions delivered in $7 \mathrm{pa}-$ tients (10.7\%).

Morbidity rates were 20\% (13/65); there were seven grade 1 , four grade 2 and two grade 3 complications.

Ten patients developed transient postoperative ascitis (defined as clinically detectable or as abdominal drainage output, when present, of $500 \mathrm{ml}$ or more per day) which resolved successfully with conservative treatment (di- 


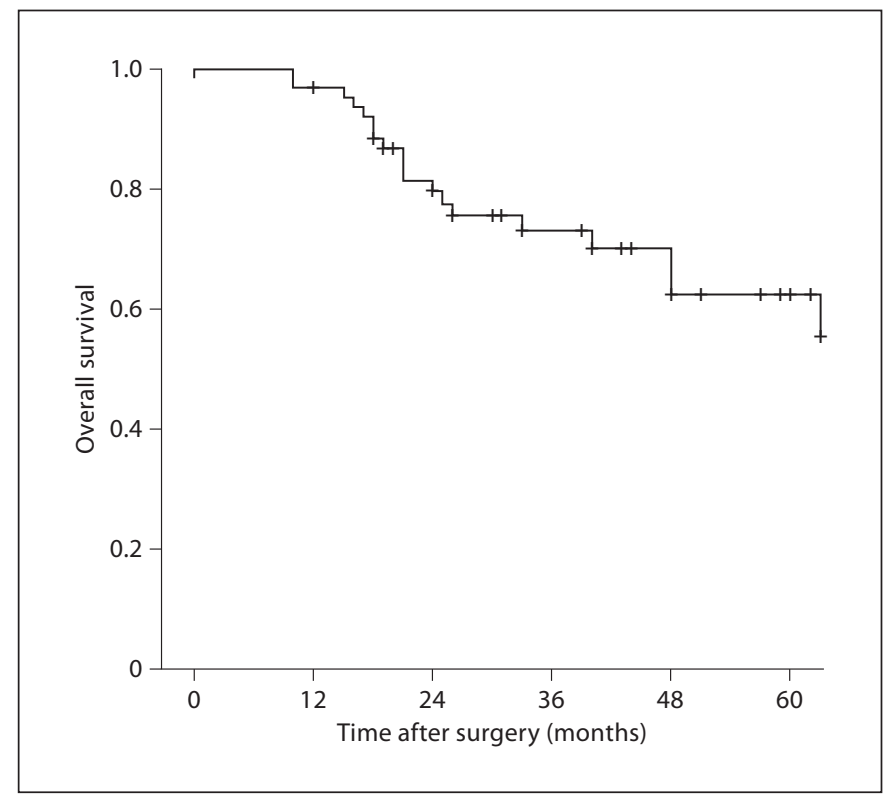

Fig. 1. Actuarial overall survival after LLR for HCC in patients with cirrhosis.

uretics). Two patients developed postoperative hemorrhage, 4 patients developed pulmonary complications, one patient each had infectious (wound infection) and cardiovascular (atrial fibrillation) complications, and one had an abdominal wall complication.

No patient had postoperative encephalopathy, bile leak or intra-abdominal abscess.

Thirty-day mortality rate was $1.5 \%$ ( 1 of 65 ) with a single death related to severe respiratory distress syndrome 3 days after surgery. Reoperation was required in both patients who had postoperative hemorrhage. The overall mean postoperative hospital stay was 8.2 (2.6; 3-15) days.

\section{Survival and Pattern of Recurrence}

Taking hospital deaths into account, the actuarial overall 1-, 3-, and 5-year survival rates were 95, 70, and $55 \%$, respectively, with a median overall survival of 75 months (95\% confidence interval, CI: 57-92; fig. 1). Excluding the one hospital death, the actuarial 1-, 3-, and 5 -year disease-free survival rates were 81,62 , and $32 \%$, respectively, with a median overall disease-free survival of 42 months (95\% CI: 18-65; fig. 2).

To examine whether there were certain clinical subsets of patients who had a less favorable outcome after resection, the patients were stratified in turn by several

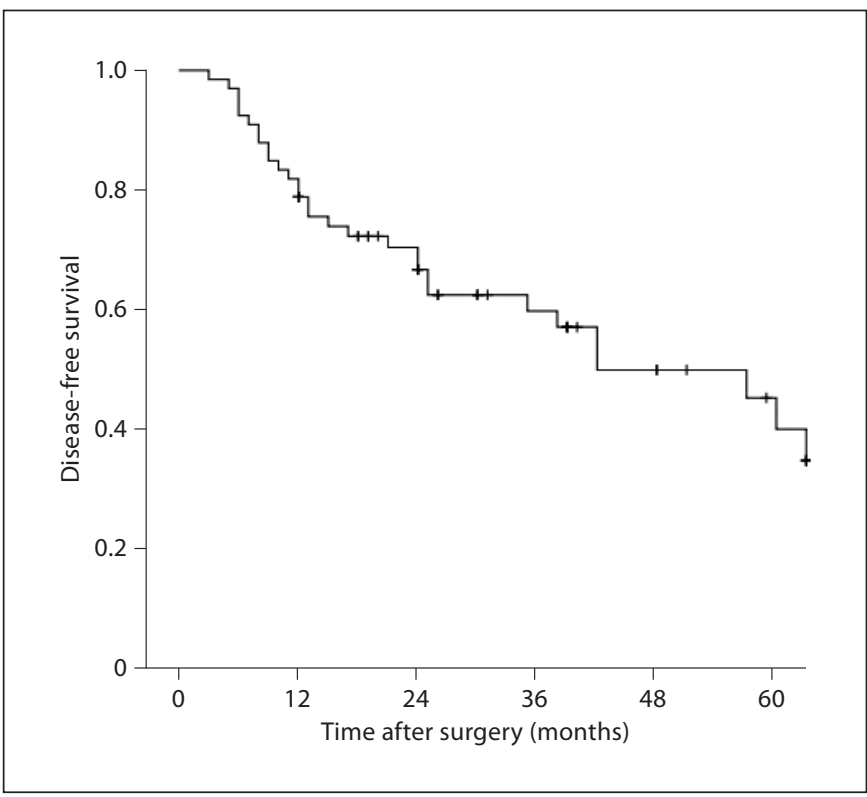

Fig. 2. Overall disease-free survival after LLR for HCC in patients with cirrhosis.

potential prognostic factors. Factors associated with survival and disease free survival are shown in table 2.

On univariate analysis, female patients $(\mathrm{p}=0.024)$, patients with a lower tumor grade $(\mathrm{p}=0.0003)$ and without microvascular invasion $(\mathrm{p}=0.0001)$ had a significantly better survival. On multivariate analysis, tumor grade (OR: 3.5, 95\% CI: 1.1-10.7, $\mathrm{p}=0.026$ ) and microvascular invasion (OR: 4.9, 95\% CI: $1.2-18.8, \mathrm{p}=0.020$ ) resulted as independent predictors of overall survival (table 2).

Female patients $(\mathrm{p}=0.033)$ with a bilirubin of $\leq 1 \mathrm{~g} / \mathrm{dl}$ $(\mathrm{p}=0.021)$, a lower tumor grade $(\mathrm{p}=0.00001)$, without satellite tumor $(\mathrm{p}=0.00001)$, a surgical margin $>1 \mathrm{~cm}$ $(\mathrm{p}=0.014)$ and without microvascular invasion $(\mathrm{p}=$ 0.0001 ) had a more favorable disease-free survival on univariate analysis.

On multivariate analysis, gender (OR: 3.4, 95\% CI: 1.1$10.2, \mathrm{p}=0.023$ ), satellite tumor (OR: $4.3,95 \% \mathrm{CI}: 1.5-12.3$, $\mathrm{p}=0.006)$, microvascular invasion (OR: $3.3,95 \% \mathrm{CI}: 1.0-$ $10.1, \mathrm{p}=0.036)$ and surgical margin (OR: 3.7, 95\% CI: 1.0 $10.1, \mathrm{p}=0.036)$ were identified as independent prognostic predictors of disease-free survival (table 2). After a median follow-up of 29 (range 3-81) months, 31 (48\%) out of 64 patients had recurrence. The cumulative recurrence rates at 1,3 , and 5 years were 19,39 , and $68 \%$, respectively.

Solitary IHRs were treated by further surgery (10 patients), RFA (4) and transcatheter arterial embolization 
Table 2. Factors associated with survival and disease-free survival

\begin{tabular}{|c|c|c|c|c|c|}
\hline Variable & Patients & $\begin{array}{l}\text { Median } \\
\text { months }\end{array}$ & $\begin{array}{l}\mathrm{p} \\
\text { (univariate) }\end{array}$ & $\begin{array}{l}\mathrm{p} \\
\text { (multivariate) }\end{array}$ & OR $(95 \% \mathrm{CI})$ \\
\hline \multicolumn{6}{|l|}{ Survival } \\
\hline Gender & & & 0.024 & 0.069 & \\
\hline Female & 27 & 75 & & & \\
\hline Male & 38 & 48 & & & \\
\hline Edmonson-Steiner grade & & & 0.0001 & 0.026 & $3.5(1.1-10.7)$ \\
\hline 1 or 2 & 43 & 75 & & & \\
\hline 3 or 4 & 22 & 26 & & & \\
\hline Microvascular invasion & & & 0.0001 & 0.020 & $4.9(1.2-18.8)$ \\
\hline Yes & 23 & 25 & & & \\
\hline No & 42 & 75 & & & \\
\hline \multicolumn{6}{|l|}{ Disease-free survival } \\
\hline Gender & & & 0.033 & 0.023 & $3.5(1.1-10.2)$ \\
\hline Female & 26 & 60 & & & \\
\hline Male & 38 & 25 & & & \\
\hline Bilirubin & & & 0.021 & 0.406 & \\
\hline$\leq 1 \mathrm{~g} / \mathrm{dl}$ & 43 & 60 & & & \\
\hline$>1 \mathrm{~g} / \mathrm{dl}$ & 21 & 25 & & & \\
\hline Satellite tumor & & & 0.0001 & 0.006 & $4.3(1.5-12.3)$ \\
\hline Absence & 50 & 60 & & & \\
\hline Presence & 14 & 17 & & & \\
\hline Edmonson-Steiner grade & & & 0.0001 & 0.206 & \\
\hline 1 or 2 & 42 & 60 & & & \\
\hline 3 or 4 & 22 & 12 & & & \\
\hline Microvascular invasion & & & 0.0001 & 0.036 & $3.3(1.0-10.1)$ \\
\hline Yes & 41 & 60 & & & \\
\hline No & 23 & 13 & & & \\
\hline Surgical margin & & & 0.0014 & 0.022 & $3.7(1.2-11.8)$ \\
\hline$\leq 1 \mathrm{~cm}$ & 12 & 13 & & & \\
\hline$>1 \mathrm{~cm}$ & 52 & 60 & & & \\
\hline
\end{tabular}

(TACE; 3), whereas patients with an oligonodular IHR were treated by TACE (4), RFA (2) and combined redosurgery plus RFA (1). Four patients with a multinodular IHR had TACE (3), and the 4th patient refused any form of therapy. Of the 2 patients who developed EHR, only one patient with lung metastases was treated by systemic chemotherapy. One patient with concurrent IHR and EHR did not receive any treatment. The overall 1-year survival rate from the time of recurrence was $47 \%$.

\section{Discussion}

A number of reports on minor LLR of HCC in patients with liver cirrhosis $[15,16]$ have been previously reported confirming the technical feasibility and safety of this technique. Laparoscopic major hepatectomies have been performed in only a limited number of cases by a few surgeons with expertise in the advanced laparoscopic approach and sufficient training in open liver surgery [17]. The present series of 65 highly selected patients has confirmed the feasibility and safety of the procedure, with a low mortality (1.5\%) and morbidity rate (20\%).

Laparoscopic resection was performed successfully in almost $90 \%$ of patients, with seven procedures requiring conversion to open surgery. The authors' institution started a specific program of LLR, and has become a referral center for the management of HCCs eligible for such an approach. Good perioperative results were previously reported [7] when highly selected small subcapsular lesions were the main indication for laparoscopic resection. These results were confirmed in the present study, which included larger tumors, six major resections and an almost threefold increase in bisegmentectomies. 
These findings reflect the impact of the learning curve on patients previously deemed unsuitable for a laparoscopic approach.

Since the 1990s, several groups have reported longterm results after open liver resection for HCC in cirrhotic liver, with a 5 -year survival rate of $50 \%$ but also a $70 \%$ recurrence rate $[18,19]$. The present authors have already shown adequate long-term survival and recurrence after LLR of HCC is achieved compared with open surgery, when stratified for tumor characteristics known to be related to survival outcome [20].

In the present study, two tumor factors, i.e. grade and microvascular invasion, were found to be predictors of overall survival after LLR on multivariate analysis. Other authors have identified Edmonson-Steiner grade as a controversial prognostic factor of survival [21]. In this series, patients with Edmonson-Steiner grades 3 or 4 had a significantly higher relative risk of death when compared to patients with Edmonson-Steiner grades 1 or 2 . Microvascular invasion, a well-known risk factor for poor survival after hepatectomy for HCC has been defined as the strongest predictor of intrahepatic metastasis caused by spread of cancer cells via the portal venous system [22].

In the present study, microvascular invasion had also a negative impact on disease-free survival. HCC is characterized by its propensity for vascular invasion and the presence of microscopic venous invasion is the most consistently reported risk factor for recurrence after resection of HCC [23]. Satellite tumor, surgical margin and gender were the other factors independently associated with disease-free survival. The presence of satellite nodules is an indicator of tumor invasiveness. Increased incidence of postoperative recurrence in association with satellite nodules has been well documented [24]. Concerning the surgical margin, the optimal liver resection margin is still controversial probably because of the difference in the selection of the patients [25]. Shi et al. [26] have recently conducted a prospective randomized trial that found in patients with macroscopically solitary HCC (especially if $\leq 2 \mathrm{~cm}$ ) a resection margin aiming grossly at $2 \mathrm{~cm}$ decreased postoperative recurrence rate and improved survival outcomes when compared with a gross resection margin aiming at $1 \mathrm{~cm}$. Accordingly, a $1-\mathrm{cm}$ resection margin might be adequate for the majority of the patients, with a better disease-free survival in those with a surgical margin of more than $1 \mathrm{~cm}$ as shown in this study. The finding of female sex as a favorable factor for long-term disease-free survival compared to male is an interesting one that had not yet been reported. Pre- viously, Fukuda et al. [27] have reported female patients were predominant among the 10-year survivors, highlighting the potential role androgen plays in liver carcinogenesis and IHR. The present study showed no negative effect of the laparoscopic approach on tumor recurrence rate.

Patients had neither port-site metastases nor intra-abdominal seeding or recurrences at the operation site. Most recurrences were intrahepatic, of which more than twothird consisted of a solitary tumor. Early recurrences after open liver resection appear to arise mainly from intrahepatic metastases, whereas late recurrences are more likely to be multicentric in origin, suggesting that different strategies may be needed for the prevention and management of early and late IHRs [28]. In the present study, all but 2 patients were managed with some form of treatment either for IHR or EHR. These data add further evidence for the impact that an effective treatment of recurrence may have on improved survival after hepatectomy for HCC [29]. This prospective observational study has confirmed the feasibility and safety of LLR in selected patients with HCC in cirrhotic liver, and proved that it can warrant long-term outcome similar to those reported with the traditional open approach.

\section{Disclosure Statement}

The authors have nothing to disclose.

References

1 Cherqui D, Laurent A, Tayar C, Chang S, Van Nhieu JT, Loriau J, et al: Laparoscopic liver resection for peripheral hepatocellular carcinoma in patients with chronic liver disease. Ann Surg 2006;243:499-506.

2 Chan ACY, Poon RTP, Ng KKC, Lo CM, Fan ST, Wong J: Changing paradigm in the management of hepatocellular carcinoma improves the survival benefit of early detection by screening. Ann Surg 2008;247:666673

3 Yao FY, Bass NM, Nikolai B, Davern TJ, Kerlan $\mathrm{R}, \mathrm{Wu} \mathrm{V}$, et al: Liver transplantation for hepatocellular carcinoma: analysis of survival according to the intention-to-treat principle and dropout from the waiting list. Liver Transpl 2002;8:873-883.

$4 \mathrm{Cha} \mathrm{CH}$, Ruo L, Fong Y, Jarnagin WR, Shia J, Blumgart LH, et al: Resection of hepatocellular carcinoma in patients otherwise eligible for transplantation. Ann Surg 2003;238: 315-321, discussion 321-323. 
5 Dagher I, Lainas P, Carloni A, Caillard C, Champault A, Smadja C, et al: Laparoscopic liver resection for hepatocellular carcinoma. Surg Endosc 2008;22:372-378.

6 Kaneko H, Takagi S, Otsuka Y, Tsuchiya M, Tamura A, Katagiri T, et al: Laparoscopic liver resection of hepatocellular carcinoma. Am J Surg 2005;189:190-194.

7 Belli G, Fantini C, D’Agostino A, Cioffi L, Langella S, Russolillo N, et al: Laparoscopic versus open liver resection for hepatocellular carcinoma in patients with histologically proven cirrhosis: short- and middle-term results. Surg Endosc 2007;21:2004-2011.

8 Strasberg SM, Belghiti J, Clavien PA, Gadzijev E, Garden JO, Lau W-Y, et al: The Brisbane 2000 terminology of liver anatomy and resections. HPB 2000;2:333-339.

9 Belli G, Fantini C, D’Agostino A, Belli A, Russolillo N: Laparoscopic liver resections for hepatocellular carcinoma (HCC) in cirrhotic patients. HPB (Oxford) 2004;6:236246.

10 Belli G, Fantini C, D’Agostino A, Belli A, Cioffi L, Russolillo N: Laparoscopic left lateral hepatic lobectomy: a safer and faster technique. J Hepatobiliary Pancreat Surg 2006; 13:149-154.

11 Belli G, Fantini C, D’Agostino A, Cioffi L, Limongelli P, Russo G, et al: Laparoscopic segment VI liver resection using a left lateral decubitus position: a personal modified technique. J Gastrointest Surg 2008;12:22212226.

12 Yamanaka N, Tanaka T, Tanaka W, Yamanaka J, Yasui C, Ando T, et al: Laparoscopic partial hepatectomy. Hepatogastroenterology 1998;45:29-33.
13 Dindo D, Demartines N, Clavien P: Classification of surgical complications: a new proposal with evaluation in a cohort of 6,336 patients and results of a survey. Ann Surg 2004; 240:205-213.

14 Edmondson HA, Steiner PE: Primary carcinoma of the liver: a study of 100 cases among 48,900 necropsies. Cancer 1954;7:462-503.

15 Viganò L, Tayar C, Laurent A, Cherqui D: Laparoscopic liver resection: a systematic review. J Hepatobiliary Pancreat Surg 2009;16: 410-421.

16 Dagher I, Belli G, Fantini C, Laurent A, Tayar C, Lainas P, et al: Laparoscopic hepatectomy for hepatocellular carcinoma: a European experience. J Am Coll Surg 2010;211:16-23.

17 Dagher I, O’Rourke N, Geller DA, Cherqui D, Belli G, Gamblin TC, et al: Laparoscopic major hepatectomy: an evolution in standard of care. Ann Surg 2009;250:856-860.

18 Fong Y, Sun RL, Jarnagin W, Blumgart LH: An analysis of 412 cases of hepatocellular carcinoma at a Western center. Ann Surg 1999;229:790-799.

19 Grazi GL, Ercolani G, Pierangeli F, Del Gaudio $M$, Cescon M, Cavallari A, et al: Improved results o liver resection for hepatocellular carcinoma on cirrhosis give the procedure added value. Ann Surg 2001;234:71-78.

20 Belli G, Limongelli P, Fantini C, D’Agostino A, Cioffi L, Belli A, et al: Laparoscopic and open treatment of hepatocellular carcinoma in patients with cirrhosis. Br J Surg 2009;96: 1041-1048.

21 Lai ECS, Fan ST, Lo CM, Chu KM, Liu CL, Wong J: Hepatic resection for hepatocellular carcinoma. An audit of 343 patients. Ann Surg 1995;221:291-298.
22 Nagao T, Inoue S, Yoshimi F, Sodeyama M, Omori Y, Mizuta T, et al: Postoperative recurrence of hepatocellular carcinoma. Ann Surg 1990;211:28-33.

23 Okada S, Shimada K, Yamamoto J, et al: Predictive factors for postoperative recurrence of hepatocellular carcinoma. Gastroenterology 1994;106:1618-1624.

24 Nagasue N, Uchida M, Makino Y, et al: Incidence and factors associated with intrahepatic recurrence following resection of hepatocellular carcinoma. Gastroenterology 1993;105:488-494.

25 Poon RT, Fan ST, Ng IO, Wong J: Significance of resection margin in hepatectomy for hepatocellular carcinoma: a critical reappraisal. Ann Surg 2000;231:544-551.

26 Shi M, Guo RP, Lin XJ, Zhang YQ, Chen MS, Zhang CQ, et al: Partial hepatectomy with wide versus narrow resection margin for solitary hepatocellular carcinoma. A prospective randomized trial. Ann Surg 2007;245: $36-43$.

27 Fukuda S, Itamoto T, Amano H, Kohashi T, Ohdan H, Tashiro H, et al: Clinicopathologic features of hepatocellular carcinoma patients with compensated cirrhosis surviving more than 10 years after curative hepatectomy. World J Surg 2007;31:345-352.

28 Nagao T, Inoue S, Yoshimi F, Sodeyama M, Omori Y, Mizuta T, et al: Postoperative recurrence of hepatocellular carcinoma. Ann Surg 1990;211:28-33.

29 Shimada M, Takenaka K, Taguchi K, Fujiwara Y, Gion T, Kajiyama K, et al: Prognostic factors after repeat hepatectomy for recurrent hepatocellular carcinoma. Ann Surg 1998;227:80-95. 